\title{
Q fever: new insights, still many queries
}

H de Valk (h.devalk@invs.sante.fr) ${ }^{1}$

1. French Institute for Public Health Surveillance (Institut de Veille Sanitaire, InVS), Saint Maurice, France

Citation style for this article:

de Valk H. Q fever: new insights, still many queries.

Euro Surveill. 2012;17(3):pii=20062. Available online: http://www.eurosurveillance.org/ViewArticle.aspx?Articleld=20062

When Edward Derrick named the illness he described in 1937 as Q (query) fever - 'until fuller knowledge should allow a better name' [cited in 1] - little did he know how well the name fits. Some 75 years later, the illness still deserves the name as, in spite of major advances in knowledge about the causative bacterium, reservoirs, routes of transmission and the clinical manifestations of the disease, many queries continue to puzzle clinicians, microbiologists, public health experts as well as veterinarians. $Q$ fever is a worldwide zoonosis caused by the intracellular bacterium Coxiella burnetii. The most common clinical presentation is an influenza-like illness with varying degrees of pneumonia and hepatitis [1]. Acute disease is usually self-limiting. However, chronic presentations, most often endocarditis, are life-threatening. Infections in pregnancy may lead to spontaneous abortions or premature delivery, even if the infected pregnant woman herself remains asymptomatic [2].

In Europe, the number of reported cases is low and is in contrast to results of seroprevalence studies, which suggest that between $2 \%$ and $14 \%$ of the general population have been previously infected by C. burnetii [3]. This discrepancy can be explained by the large proportion of subclinical cases, estimated be about $50 \%$. Also, the diagnosis of symptomatic cases is often missed as symptoms are non-specific. Laboratory confirmation is essential for diagnosis, but is often not sought due to low awareness of $Q$ fever among patients and practitioners outside high-incidence areas. Nevertheless, Q fever outbreaks are regularly reported throughout Europe as well as in other parts of the world. Most often the source is infected livestock and there are a limited number of cases in the vicinity of the affected farms. However, from 2007 to 2009, an outbreak of unprecedented scale occurred in the Netherlands, involving 3,523 notified human cases [4]. The Dutch health authorities faced many challenges regarding the identification and control of the source of contamination, the risk for pregnant women and other groups likely to develop chronic $Q$ fever, the strategies to be used for diagnosis, follow-up and treatment regimens of acute and chronic Q fever, and the safety of blood transfusion and organ transplantation. Consequently, the outbreak sparked a large number of research studies to address these questions. The outbreak setting created the opportunity to study several issues difficult to address in a low-incidence setting.

In 2010, given the increase in the number of cases in the Netherlands, a number of questions arose, related to the safety of blood transfusions, the need to strengthen surveillance for new cases, the impact on health of chronic $Q$ fever and the impact on health for people in risk groups, such as pregnant women. These issues were tackled in a risk assessment carried out by the European Centre for Disease Prevention and Control (ECDC) [3], at the request of the European Commission. The ECDC assessed whether an evidencebased approach, comparable to the methodology used in clinical medicine, was appropriate for giving public health advice on $Q$ fever control strategies under the time constraints of an outbreak. In this issue of Eurosurveillance, Forland et al. present a summary of their findings [5]. The most striking finding was the lack of scientific evidence for the screening and treatment regimens for $Q$ fever in pregnant women. Although a retrospective hospital-based study from France and a Canadian study emphasise that $C$. burnetti is a potential threat to pregnant women, the risk is difficult to quantify $[6,7]$. The retrospective design and selection bias of these studies may have led to overestimation of the risk.

The risk of acute $\mathrm{Q}$ fever patients developing chronic $\mathrm{Q}$ fever was estimated to be $2 \%$ [3]. Both symptomatic and asymptomatic infected patients with previous cardiac valve pathology, aneurysms or vascular grafts, with malignancies or who are immunocompromised are most at risk for developing chronic $Q$ fever. On the basis of the findings of observational studies, ECDC recommended to consider targeted case-finding among these risk groups and long-term follow-up of acute and chronic cases. However, the need to initiate prospective cohort studies and trials with control groups was emphasised, to obtain more robust evidence on how to diagnose and treat acute and chronic disease. 
Because of the theoretical possibility that $C$. burnetii can be transmitted through blood transfusion, ECDC recommended that active screening of blood and tissue products be considered, although only a few bloodborne infections have been clearly documented.

The inhalation of contaminated aerosols originating from the faeces and birth products of infected animals, most often cattle, sheep and goats, is the main route of transmission in humans. In the literature, estimates of the distance infectious particles can spread by air range from $400 \mathrm{~m}$ to $40 \mathrm{~km}$. The ECDC risk assessment team concluded that the most sound data were from a Dutch study using a geographic information system, which demonstrated that the highest risk of infection was within a radius of $5 \mathrm{~km}$ from the source [8].

Since the ECDC risk assessment, results of the large portfolio of ongoing multidisciplinary research in the Netherlands are gradually becoming available and contribute new insights and evidence. In this issue, three papers present recent findings.

Munster et al. examine the evidence base for routine C. burnetii screening among pregnant women in highrisk areas for $Q$ fever [9]. A recent population-based study in the Dutch outbreak area showed no evidence of adverse pregnancy outcome among women who had antibodies to $C$. burnetii during early pregnancy [10]. On the basis of this study and because of the potential biases in earlier retrospective studies reporting adverse pregnancy outcomes, the authors judged that there still is much uncertainty about the consequences of untreated $C$. burnetii infection during pregnancy. There is also no consensus about the screening method or treatment. Therefore, they conclude that at this stage, there is no evidence on the effectiveness of a $C$. burnetii-screening programme in the present Dutch setting.

Van der Hoek et al. describe how, in the aftermath of the outbreak in the Netherlands, the priorities are shifting from detection and management of acute cases and control of transmission to the follow-up of acute $Q$ fever patients, screening of groups at risk for chronic $Q$ fever, screening of blood and tissue, and human vaccination [11]. Although there seems to be an international consensus on the groups most at risk for chronic $Q$ fever, the optimal follow-up strategy of acute $Q$ fever patients for the early detection and treatment of chronic $Q$ fever and the strategy for screening of people in risk groups for chronic $Q$ fever are points of controversy. There is an ongoing debate about the validity of serological profiles as predictors of chronic $Q$ fever, which serological cut-off values should be used, the exact timing and frequency of examinations and serological follow-up, and the duration of treatment [12-16]. The wide variation in serological and PCR results during the follow-up of patients with acute $Q$ fever implies that the diagnosis of chronic $Q$ fever must be based primarily on clinical grounds $[15,17]$. Van der
Hoek proposes different serological follow-up strategies for patients with and without known risk factors for chronic Q fever [15].

Another article by van de Hoek et al. in this isssue sheds light on the problem of under-diagnosis and under-reporting [18]. The authors estimate that only 7.9 $\%$ of incident infections of $C$. burnetii that occurred in the affected area of the Netherlands were notified, and that the 3,522 acute $Q$ fever cases that were notified in the country from 2007 to 2009 correspond to more than 44,000 infections in the same period. The proportion of under-diagnosed and under-reported cases is likely to vary by region and is expected to be even higher in low-incidence areas because of a lack of awareness of patients and physicians. These high numbers of undiagnosed infections constitute an additional challenge for the detection of chronic $Q$ fever.

Adoption of an evidence-based approach is challenging in infectious disease epidemiology, especially during an outbreak. Forland et al. point out that in many situations, observational studies, often retrospective, or natural experiments are the only studies available [5]. Such studies provide evidence at the lower level of the evidence hierarchy in the Grading of Recommendations Assessment, Development and Evaluation (GRADE) system [19]. However, such studies can still be of good quality and yield important information. Clearly stating the strengths and limitations of such studies not only enables the best available evidence to be used for preliminary recommendations, but also ensures transparency regarding uncertainties and allows knowledge gaps and priorities for further research to be clearly identified. The evidence base for public health policy and strategies should be continuously reassessed, whenever new evidence is made available through new studies.

An evidence-based approach and continuous updates are time- and resource-consuming. However, considering the consequences for health, the enormous resources that are often needed for the implementation of the selected strategies and the resulting higher quality of public health advice, it is beyond doubt that the investment is worth it.

\section{References}

1. Parker NR, Barralet JH, Bell AM. Q fever. Lancet. 2006;367(9511):679-88.

2. Maurin M, Raoult D. Q fever. Clin Microbiol Rev. 1999;12(4):518-53.

3. European Centre for Disease Prevention and Control (ECDC). Technical report. Risk assessment on Q fever. Stockholm: ECDC; May 2010. Available from: http://ecdc.europa.eu/en/ publications/Publications/1005_TER_Risk_Assessment Qfever.pdf

4. Schimmer B, Morroy G, Dijkstra F, Schneeberger PM, Weers-Pothoff G, Timen A, et al. Large ongoing $Q$ fever outbreak in the south of the Netherlands, 2008. Euro Surveill. 2008;13(31):pii=18939. Available from: http://www. eurosurveillance.org/ViewArticle.aspx?Articleld=18939

5. Forland F, De Carvalho Gomes H, Nokleby H, Escriva A, Coulombier D, Giesecke J, Jansen A. Applicability of 
evidence-based practice in public health: risk assessment on $\mathrm{Q}$ fever under an ongoing outbreak. Euro Surveill. 2012;17(3): pii=20060. Available from: http://www. eurosurveillance.org/ViewArticle.aspx?Articleld $=20060$

6. Carcopino X, Raoult D, Bretelle F, Boubli L, Stein A. Q fever during pregnancy: a cause of poor fetal and maternal outcome. Ann N Y Acad Sci. 2009;1166:79-89.

7. Langley JM, Marrie TJ, LeBlanc JC, Almudevar A, Resch L, Raoult D. Coxiella burnetii seropositivity in parturient women is associated with adverse pregnancy outcomes. Am J Obstet Gynecol. 2003;189(1):228-32.

8. Schimmer B Ter Schegget R, Wegdam M, Züchner L, de Bruin A, Schneeberger PM, et al. The use of a geographic information system to identify a dairy goat farm as the most likely source of an urban Q-fever outbreak. BMC Infect Dis. 2010;10:69.

9. Munster JM, Steggerda LM, Leenders AC, Aarnoudse JG, Hak E. Screening for Coxiella burnetii infection during pregnancy: pros and cons according to the Wilson and Jungner criteria. Euro Surveill. 2012;17(3):pii=20061. Available from: http:// www.eurosurveillance.org/ViewArticle.aspx?Articleld=20061

10. van der Hoek W, Meekelenkamp JC, Leenders AC, Wijers N, Notermans DW, Hukkelhoven CW. Antibodies against Coxiella burnetii and pregnancy outcome during the 2007-2008 Q fever outbreaks in the Netherlands. BMC Infect Dis. 2011;11:44.

11. van der Hoek W, Schneeberger PM, Oomen T, WegdamBlans MC, Dijkstra F, Notermans DW, et al. Shifting priorities in the aftermath of a Q fever epidemic in 2007 to 2009 in the Netherlands: from acute to chronic infection. Euro Surveill. 2012;17(3):pii=20059. Available from: http://www. eurosurveillance.org/ViewArticle.aspx?Articleld =20059

12. Million M, Thuny F, Richet H, Raoult D. Long-term outcome of $Q$ fever endocarditis: a 26-year personal survey. Lancet Infect Dis. 2010;10:527-35.

13. Limmathurotsakul D, Cooper B, Peacock SJ, De Stavola B. Long-term outcome of $\mathrm{Q}$ fever endocarditis. Lancet Inf Dis. 2011;11(2):81.

14. Limonard GJ, Nabuurs-Franssen MH, Dekhuijzen PN, Groot CA. Prevention of $Q$ fever endocarditis. Lancet Infect Dis. 2011;11(2):82-3.

15. van der Hoek W, Versteeg B, Meekelenkamp JC, Renders NH, Leenders AC, Weers-Pothoff I, et al. Follow-up of 686 patients with acute $Q$ fever and detection of chronic infection. Clin Infect Dis. 2011;52(12):1431-6.

16. Healy B, van Woerden H, Raoult D, Graves S, Pitman J, Lloyd G, Brown N, et al. Chronic $\mathrm{Q}$ fever: different serological results in 3 countries--results of a follow-up study 6 years after a point source outbreak. Clin Infect Dis. 2011;52(8):1013-9.

17. Sunder S, Gras G, Bastides F, De Gialluly C, Choutet P, Bernard L. Chronic Q fever: relevance of serology. Clin Infect Dis. 2011;53(7):749-50.

18. van der Hoek W, Hogema BM, Dijkstra F, Rietveld A,

Wijkmans CJ, Schneeberger PM, et al. Relation between Q fever notifications and Coxiella burnetii infections during the 2009 outbreak in the Netherlands. Euro Surveill. 2012;17(3): pii=20058. Available from: http://www. eurosurveillance.org/ViewArticle.aspx?Articleld $=20058$

19. Guyatt GH, Oxman AD, Vist GE, Kunz R, Falck-Ytter Y, AlonsoCoello $P$, et al. GRADE: an emerging consensus on rating quality of evidence and strength of recommendations. BMJ. 2008;336(7650):924-6. 